\section{The Ross operation in infants and children, when and how?}

\author{
Magdi Yacoub, ${ }^{1,2}$ Ismail El-Hamamsy ${ }^{3}$
}

The Ross operation is the only operation which guarantees long-term survival of the aortic valve substitute, and allows it to reproduce some of the extremely sophisticated functions of the normal living aortic valve. ${ }^{1}$ This has been shown to translate into longer survival and better quality of life in adults. ${ }^{2}$ The operation was described almost 50 years ago, ${ }^{3}$ primarily for use in growing children, to avoid anticoagulation and repeated operations. In spite of that, the exact role, timing and techniques of applying this operation for this particular group of patients are still hotly debated. ${ }^{4}$ It could be argued that application of formal decision theory could almost immediately resolve this dilemma, by constructing a decision tree based on defining outcome of alternative decisions at each node. This however, depends on the availability of accurate statistics from large databases, which simply are not available. Until recently the only available data were from small single-centre series, which were not prospective or comparative and depended heavily on the biases and experience of the particular clinicians.

The Italian multicentre registry, is a welcome addition to the literature, as it describes real-life experiences in 305 infants and children, followed up for periods of up to 23 years..$^{5}$ This registry provides extremely valuable information and lessons relating to when and how to apply the Ross operation in children. With regards to timing, the registry shows markedly increased mortality $(27.6 \%$ for infants as opposed to $0.2 \%$ for older children) and aortic reoperation rate $(20.7 \%$ vs $10.5 \%$ ) in infants undergoing the Ross operation during the 1 st year of life. Similar findings have been previously reported in single-centre series. ${ }^{6}$

How can that be explained? Several factors could be involved. The first relates to the very high use of additional Konno procedures in this age group (approximately in $2 / 3$ of the patients). This technique could destabilise the pulmonary

\footnotetext{
${ }^{1}$ Qatar Cardiovascular Research Centre, Doha, Qatar; ${ }^{2}$ Imperial College London, London, UK; ${ }^{3}$ Montreal Heart Institute, Universite de Montreal, Montreal, Canada
}

Correspondence to Professor Magdi Yacoub, Imperial College London, London, UK; m.yacoub@imperial.ac.uk plasty in infants. ${ }^{9}$ autograft, which stems from the fact that the leaflets of the pulmonary valve, unlike those of the aortic valve are directly attached to the musculature of the RV outflow (figure 1). This necessitates the insertion of the pulmonary root within the aortic 'annulus' during the Ross operation. ${ }^{7}$ The second possible factor could be related to the presence of a hypoplastic aortic annulus in infants, which could interfere with the insertion of the bulky pulmonary root. The use of valve conserving operations to allow the children to grow, instead of applying the Ross operation in infancy, has consistently given excellent results. ${ }^{8}$ It is interesting to note that in older children in the Registry, previous balloon valvuloplasty but not surgical valvotomy increased the risk of the Ross operation, supporting the application of surgical rather than balloon valvulo-

Another lesson to learn from the Registry relates to the finding that the subcoronary implantation was associated with higher rates of early and late aortic valve

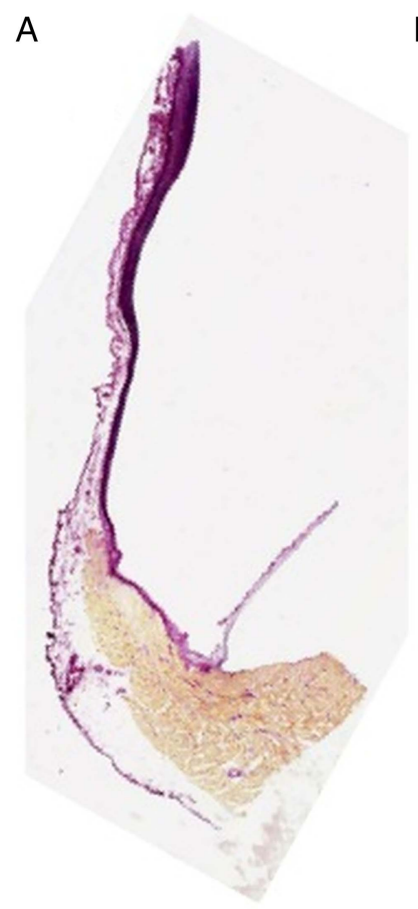

B

Figure 1 (A) Histological section of a pulmonary root stained by elastic van Gieson showing the attachment of the cusps to the right ventricular outflow tract muscle and the absence of a distinct fibrous annulus. (B) Histological section through the aortic root showing a well-defined fibrous annulus linking the aortic leaflet to the media of the sinus of Valsalva. homograft in the pulmonary position. This is almost certainly due to the use of large pulmonary homografts (oversizing), which we believe is necessary at all ages particularly in children to avoid late stenosis. It is hoped that lessons learned from large registries with long careful follow-up like that of the Italian multicentre registry will help in optimising the results of the Ross operation at all ages, and address the major concerns regarding the current under use of this operation. ${ }^{10}$

Contributors Both authors contributed to this editorial.

\section{Competing interests None.}

Provenance and peer review Commissioned; internally peer reviewed.

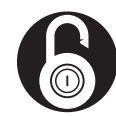

\section{OPEN ACCESS}
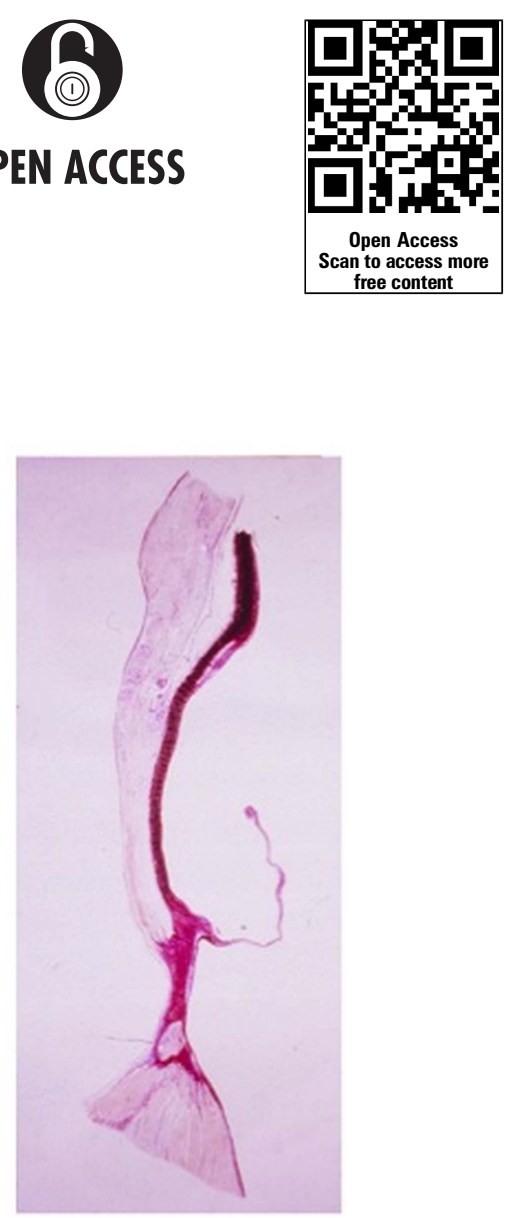

failure. This could be due to the fact that in spite of concerns regarding late dilatation, the use of a free-standing root avoids distortion and guarantees optimal relationship between the different components of the autograft valve mechanism. ${ }^{7}$

Finally, the authors report a relatively low incidence of reoperation on the 


\section{Editorial}

Open Access This is an Open Access article distributed in accordance with the Creative Commons Attribution Non Commercial (CC BY-NC 4.0) license, which permits others to distribute, remix, adapt, build upon this work non-commercially, and license their derivative works on different terms, provided the original work is properly cited and the use is noncommercial. See: http://creativecommons.org/licenses/ by-nc/4.0/

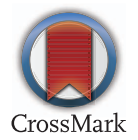

To cite Yacoub M, El-Hamamsy I. Heart 2014;100:1905-1906.

Accepted 25 September 2014

Published Online First 16 October 2014

\section{SLinked}

http://dx.doi.org/10.1136/heartjnl-2014-305873
Heart 2014;100:1905-1906.

doi:10.1136/heartjnl-2014-306453

\section{REFERENCES}

1 Chester AH, El-Hamamsy I, Butcher JT, et al. The living aortic valve: From molecules to function. Global Cardiol Sci Pract 2014;2014:52-77.

2 El-Hamamsy I, Eryigit Z, Stevens LM, et al. Long-term outcomes after autograft versus homograft aortic root replacement in adults with aortic valve disease: a randomised controlled trial. Lancet 2010;376:524-31.

3 Ross DN. Replacement of aortic and mitral valves with a pulmonary autograft. Lancet 1967; 2:956-8.

4 Jonas RA. The Ross procedure is not the procedure of choice for the teenager requiring aortic valve replacement. Semin Thorac Cardiovasc Surg Pediatr Card 2005:176-80.

5 Luciani GB, Lucchese G, Carotti A, et al. Two decades of experience with the Ross operation in neonates, infants and children from the Italian Paediatric Ross Registry. Heart 2014;100: 1954-9.
6 Tan Tanny SP, Yong MS, d'Udekem Y, et al. Ross Procedure in Children: 17-Year Experience at a Single Institution. J Am Heart Assoc 2013;2: e000153.

7 Yacoub MH, Kilner PJ, Birks EJ, et al. The aortic outflow and root: a tale of dynamism and crosstalk. Ann Thorac Surg 1999;68:S37-43.

8 Rehnstrom P, Malm T, Jogi P, et al. Outcome of surgical commissurotomy for aortic valve stenosis in early infancy. Ann Thorac Surg 2007;84: 594-8.

9 McElhinney DB, Lock JE, Keane JF, et al. Left heart growth, function, and reintervention after balloon aortic valvuloplasty for neonatal aortic stenosis. Circulation 2005:111:451-8.

10 Yacoub MH, El-Hamamsy I, Sievers HH, et al. Under-use of the Ross operation--a lost opportunity. Lancet 2014;384:559-60. 